recovered, and can walk without inconvenience. The leg is nearly as strong as the right. Dense masses of bone fill up the interval of from five to six inches the removed bone left. The leg is shortened by about three quarters of an inch, but is natural in appearance, with the exception of the knee being a little too much rotated outwards, some bulging at the middle third, and the slightly depressed cicatrices in front.

In conclusion I would remark, that I attribute this re. covery almost entirely to the suppression of undue inflam. matory action by the cold water douching; also to careful attention being paid to the constitution, especially avoiding disturbance to the dig-stive organs by purgatives; and to perfect rest and non-interference as regards the limb by too much probing, handling, dressing, bandaging, or movement of the body.

Biarritz, 1863.

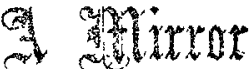

OF THE PRACTIOE OF

\section{MEDICINE AND SURGERY IN THE}

\section{HOSPITALS OF LONDON.}

Nulla est alia pro certo noscendi via, nisi quam plurimas et morborum et dissectionum historias, tam aliorum proprias, collectas habere et inter so comparare.-MoresenI. De Sed.et Caus. Morb., lib. 14. Procmiam.

\section{WESTMINSTER HOSPITAL.}

CLOSURE OF THE JAWS BY RIGID CICATRICES AND BY A BRIDGE OF BONE; INTERNAL DIVISION, AND SUBSEQUENT TREATMENT BY SHLVER CAPS AND SHIELDS AFFIXED TO THE TEETH.

(Under the care of Mr. BARNARd HoLT.)

IN The LANCET of Oct. 25th, 1862, we recorded an example of closure of the jaws from cicatrices successfully treated in this hospital by Mr. Heath, who removed a portion of the lower jaw and formed a false joint in the manner proposed by Professor Esmarch. To-day we record a somewhat similar case treated in the same hospital by $\mathbf{M r}$. Holt, by incisions within the mouth, and subsequently by metal shields adapted to the teeth, the result of which has been effectually to provent reunion of the cheek and gums, and to give the patient a most satisfactory amount of movement of the jaw.

Frances $\mathrm{H}-$, aged seventeen, was admitted July 3rd, 1862, suffering from closure of the jaws. In 1857 the patient had fever, attended with an abscess in the cheek on the right side, which led to such contraction and adhesion of the mucons membrane to the jaw as to cause great difficulty in opening the mouth. This difficulty continued to increase, and attempts were made, by direction of the surgeon under whose charge she was, to force open the mouth with a spoon-frequently used, but to no purpose. Early in March, 1859, she had scarles fever very slightly; and in the following August she was sent to the Kent and Canterbury Hospital, where several of her teeth were extracted, and an iron screw was used to force open the mouth, but without permanent benetit. On Nov. $29 \mathrm{ih}, 1860$, she was admitted into the Westminster Hospital, when Mr. Holt divided the bands of cicatrix within the cheek freely, and by careful dressing she obtained some power over the jaw, and was discharged in January, 1861.

On being again admitted July 3 rd, 1862 , she presented the following condition:- The mouth is contracted on the right side, but not sufficiently to prevent the lips from opening to expose the front teeth. The jaws are firmly closed, the upper overlapping the lower incisors in the ordinary way, allowing a space of one-sixteenth of an inch between them, through which food is introduced. The right cheek is very dense and rigid, and there is a considerable depression in it. The finger camnot be introduced beyond the canine teeth, owing to the firm adhesions of the cheek to the gums; while on the left side the mucous membrane of the cheek is free and healthy. The patient's general health is good, as she takes sufficient food, although slowly.

Seeing the amount of deformity which resulted from Esmarch' operation in Mr. Heath's case, although in other respects $\mathrm{v}$ ery satisfactory, Mr. Holt greferred and deternined to adopt the plan proposed and successfully carried out by $\mathrm{Mr}$. Clendon, dental surgeon to the hospital, in a case under the care of the late Mr. B. Phillips, and also in another of his own in private practice-namely, to operate from the front of the mouth, to separate the cheek freely from all adbesions, and employ mechanical means to prevent the possibility of their reunion.

The operation was performed on the 23rd of July. The patient having been placed nnder chloroform, Mr. Holt divided the cicatrices freely within the mouth, separating the cheek from the upper and lower jaws until the finger reached well back to the ramus of the jaw. When this had been effected the jaw still remained fixed, and it was found that the teeth of the lower jaw, from the hicuspids backwards, had been thrust inwards, and that from the outer margin of the alveolus in this region a firm plate of bone extended to the alveolus of the upper jaw, and effectually prevented any movement. With a narrow saw introduced into the mouth, Mr. Holt succeeded in dividing this, and the mouth could then be opened, after which the remains of the ridge were removed with tie bone-forceps. The cheek was stuffed with oiled lint to prevent the recurrence of the adhesions, and the patient was put to bed.

July 25th. - There was considerable swelling of the face; the lint was therefore removed, and the finger passed freely in every direction; after which the lint was replaced.

$28 \mathrm{th}$. - The swelling of the face having somewhat subsided, Mr. Clendon took wax and gutta-percha impressions of the month, under chloroform, in order to form the shields to be attached to the teeth and inserted between the cheek and gums.

30th. - The shields were fitted. They consist of a horizontal portion fitting upon the molar teeth, and fastened with bands to the canine and incisor teeth, and a vertical portion which passes by the side of the alveolus to the bottom of the sulcus between it and the cheek. The edge of this is quite thin, and

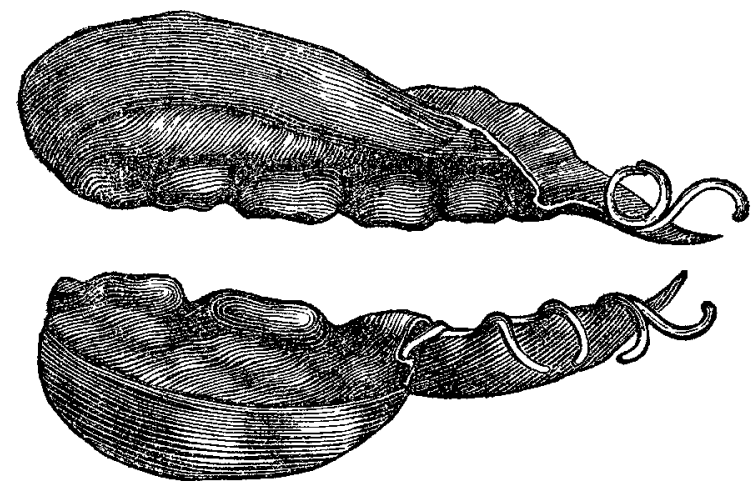

serves to cut a groove in the adhesions which are already beginning to fill up the space.

Aug. 7th. - The shields keep thoroughly in their places; but as the cheek is stili raw, wet lint is inserted between the gams and the lining of the cheek, and the finger is daily passed freely beneath the cheek to the full extent of the teeth. Two wedges of wood were fitted to the mouth, one on each side, so as to maintain the constant separation of the jaws.

$15 \mathrm{th}$. The condition of the mouth is in every way satisfactory ; the gums and cheek are beginning to be covered with mucous membrane, and the discharge is slight. A band in the middle of the cheek having become racher tense and prominent, it was freely cauterized with nitrate of silver.

Sept. 1st. - The shields and wedges are worn without discomfort, and the girl can open her mouth most satisfactorily. The shields effectually prevent adhesious forming between the gum and the chesk.

From this time the patient's progress was uninterrupted. She recovered perfect use of her jaw and mouth, and all tendency to recontraction seemed to have disappeared. The girl was kept under observation at the hospital many weeks longer than was absolutely necessary for the further carrying out of the treatment, with the view of testing the permanence of the cure, and was finally sent into the country on November lst, 1862 , with the shields still in the mouth, and still wearing one of the wedges, which she had become quite accustomed to.

She returned to the hospital for a few days in December that the progress might be noted, and the accompanying portrait (from a photograph) was then taken for the sake of comparison with that given in THe LANCeT of Oet. $25 \mathrm{ch}, 1862$, p. 444, showing the result of Esmarch's operation. The shields were removed for five days in order to be sketched, and no apparent change resulted from their non-use; but, for the sake of safety, 
she is to continue wearing them for the present. The distance between the incisor teeth, when the mouth is wide open, is three-quarters of an inch.

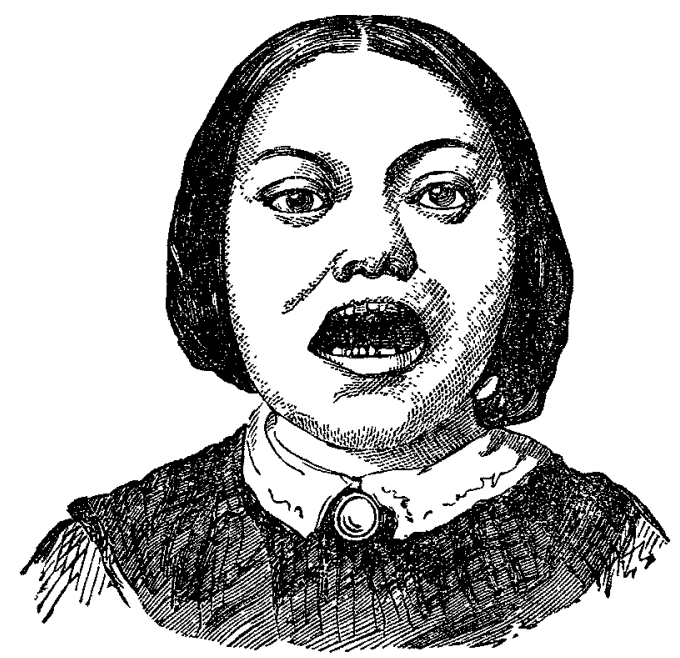

KING'S COLLEGE HOSPITAL.

AUTOPLASTIC OPERATIONS AFTER A SEVERE BURN; SUCCESSFUL TRANSPLANTATION OF INTEGUMENTS FROM THE ABDOMEN TO THE ARM.

(Under the care of Mr. Wood.)

Lydra $W-$ aged eight years and nine months, was admitted into the hospital in January, 1862, for a severe burn, destroying the skin extensively on the left side of the front of the neck and chin, and over the posterior surface of the left wrist and forecrm, and scorching in a less degree the front of the right elbow. After remaining in the hospital till the month of April, she was discharged. A broad, hard, contracting cicatrix, binding down the chin to the sternum; an extensive cicatrizing surface on the back of the left wrist, with a sore extending up to the elbow, drawing the hand backwards upon the forearm; and a cicatrization over the front of the right elbow, remained at the time of her discharge.

In the month of Septemher she was again admitted, under Mr. Wood. 'The chin was drawn down to within an inch of the sternum, and the left corner of the mouth was distorted by a band of hard, thick, and tongh cicatrix, an inch and a half wide, placed a little to the left of the median line. On the right side of this the skin was depressed, and puikered into a loose bag or hollow; on the left side of the neck it was tight and drawn, and marked by extensive cicatrices, especially towards the ear and angle of the lower jaw, where the widest diameter of the cicatrix was transverse. The left hand was drawn back upon the forearm, the wrist-joint being completely reversed by the contraction of a falciform cicatrix situated opposite to the ring finger, extending from near its metacarpo phalangeal articulation to three inches above the wrist joint. The little finger was drawn to within an inch of the back surface of the forearm, the other digits being placed at increasing angles. The joints at the roots of the fingers, especially the little and ring fingers, were also reversed. An extensive sore, which had remained stationary since her discharge, extended up to near the inner condyle. The whole of the skin of the forearm, with the exception of a narrow patch on the outside, was seamed with cicatrices. The right arm was contracted at the elbow, and could not be strainhtened to much more than a right angle. The girl was in good health, with a clean tongue and good appetite.

Treatiment. - The right arm was first extended gradually by the application of a straight splint in front, with graduated pads placed at the bend of the elbow, and withdrawn one by one from day to day.

On the lith of October, 1-62, the child was brought into the theatre to be operated on for the deformity of the neck. A straight, narrow.bladed knife was pushed through the skin behind the upper part of the cicatrix, and drawn downwards and forwards towards the steruum, dividing the cicatrix obliquely from the breast-bone. The head being then thrown well back, the cicatrix w*s dissected freely upwards towards the ear, and the edges of the wound raised from the deeper parts all round.
On the right side the dissection was carried under the puckered pouch of skin there found, and the incision prolonged trans. versely from the lower end, so as to loosen it and spread it out in to a quadrangular flap of skin, which was then brought across the neci over the site of the cicatrix, the latter being pushed up high towards the angle of the jaw. The edges were then secured by wire sutures to the skin on the left side of the neck and to the displaced cicatrix above. At the lower edge of the flap was left an open wound to heal by granulation. The head was beld back, and the chin raised by a bandage passing round the head, down the back, and round the waist, and the wound dressed with wet lint and gutta-percha skin.

After the operation a good deal of the upper border of the wound became adherent, but on the left side there remained for some time an open sore, which, with the exposed surface left by the transposition of the flap, gradually healed up, and by the end of the month was nearly closed, leaving the chin elevated, and the motions of the head free and unimpeded.

The persistent and extensive sore remaining on the left arm, the extreme contraction of the cicatrix already formed, the great hack ward distortion of the hand, and the small quantity of healthy skin remaining upon the forearm rendering hopeless all attempis to restore its normal prisition by gradual extension or transposition of adjacent skin, Mr. Wood resolved to attempt the grafting or transplantation of skin from the surface of the belly. A careful preliminary adjustment of an easy position of the arm on the trunk heing inade, a thin sheet of gutta-percha was moulded in the usual manner over the front of the chest, in the manner of a cuirass, overlapping well the sides of the chest, and hollowed out at the position of the armpits. At its left border was left attached a flan ye piece of the length of the upper arm, which was curved round the back and outer sides in the manner of a soroll splint. From its lower border, which reached to within three inches of the umbilicus, projected at right, angles another piece to support the forearm, placed at an oblique angle with the upper. The body part of the cuirass was punchert over with holes, and the whole well padded with cotton wool, and covered with leather. The apparatus was secured to the body by a strap round the shoulders and back of the neck, and held in its place by broad adhesive straps and bandage. When placed in pnsition, and the arm laid on the abdomen, the centre of the cicatrix was situated ahove and a little to the left of the umbilicus, so that a flap raised from the integumen's at that place would receive into its base the branches of the superficial epigastric artery, coming from below upwards and in wards.

On the 5th of November the child was again brought into the operating theatre and placed under chloroform. A lancetshaped flap of skin two inches and a half long, with its apex upward, and a base of the same width directed towards the left groin, was then raised from the surface of the belly a little above and to the left side of the navel. The thickness of the flap was gradually increased towards the base, where the a poneurosis of the external oblique was a little exposed. The edges of the wound were then bronght together by the use of a pair of rectangular pins passing in opposite directions, and fastening to each other's loous so as to form a quadrangle, with the ends well covered with lint and padded with cotton-wool. Over these a thick dressing of simple cerate and cotton-wool was laid. A transverse incisicn was next made across the mindle of the falciform cicatrix on the back of the left wrist, directly opposite the joint, and carried sufficiently far to permit the hand and fingers to be straightened out in a direct line with the forearm. No dissection was made, nor were the edges of the cut raised from the deeper parts. The surfaces of the wounds were then carefully washed with lukewarm water until the bleeding had completely ceased. The hand was then laid upon the abdomen and strapped to the body-splint in a straightener position, and then aljusted so as to bring the surface of the wound easily under that of the flap raised from the belly, the hand resting directly over the wound left by raising the flap. Another $p$ ir of rectangular pins were then passed right through the centre of the flap, about an inch apart, and through the integuments at the outer side of the skin of the forrarm, so as to obtain a deep and firm hold. The pins when locked into each other's loops formed a quadrangle, the ends of which were well padded where they rested on the surfaces of the flap and skin of the forearm, the padding being adjusted so that by abstracting from or adding to it the pressure upon the centre of the flap could be regulated to a nicety according to the desree of swelling in the flap after the opera. tion. A few wire sutures were placed around the edge of the flap, the point of its lancet shape being fixed into the anyle of the cut across the wrist. A pad of lint was placed across the 